\section{Late-Breaking Abstracts}

\section{Biomarkers, Immune Monitoring, and Novel Technologies}

\section{CHARACTERIZATION OF THE IMMUNE LANDSCAPE OF MALIGNANT PLEURAL EFFUSION COMPOSITION FROM PATIENTS WITH METASTATIC BREAST CARCINOMA: A PILOT STUDY}

Caddie Dy Laberiano*, Edwin Parra, Qiong Gan, Heladio Ibarguen, Shanyu Zang, Esther Yoon. The University of Texas MD Anderson Cancer Center, Houston, TX, USA

Background Breast cancer(BC) is the second most common cause after lung cancer of malignant pleural effusions(MPEs), in approximately one third of all MPEs.Although,MPEs are relativity easy to be collated are still not well characterized in their cellular compositions. This opens new avenues to characterize the cellular milieu comprising the MPE, as it has the potential to be highly informative about mutational markers and immune response -ultimately guiding targeted therapy and predicting therapeutic outcomes with their study. The proposed study will characterize immune landscape of the cellular composition of MPE from patients with metastatic breast carcinoma and characterize their relationship with clinicopathologic features in these patients.

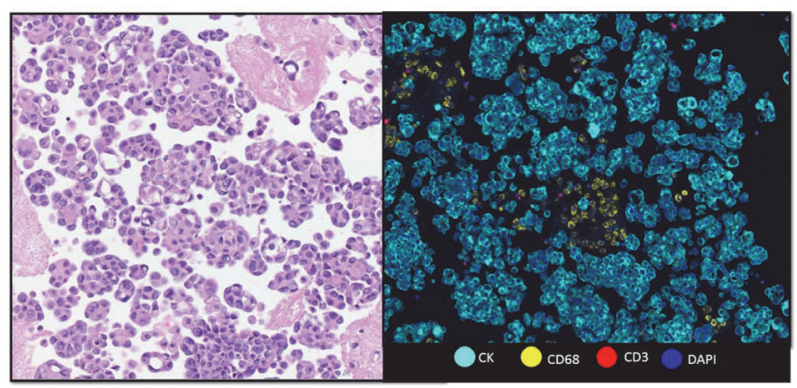

Abstract 945 Figure 1 Comparison between the cell block in $\mathrm{H}-\mathrm{E}$ and $\mathrm{mIF}$ expression $\mathrm{CK}, \mathrm{CD} 68$ and $\mathrm{CD} 3$

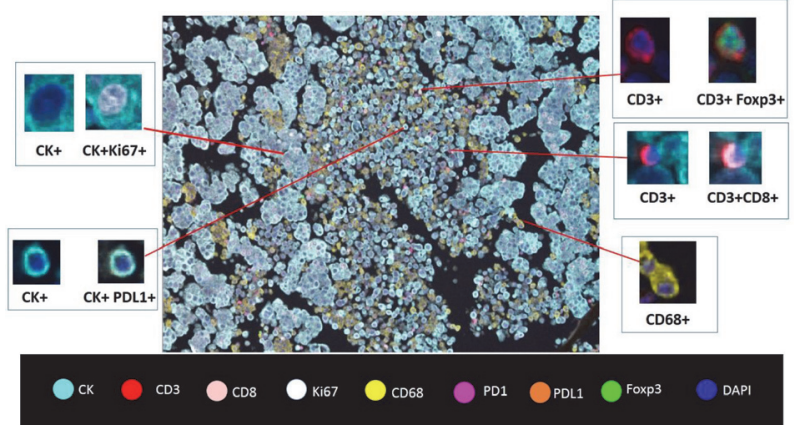

Abstract 945 Figure 2 Composite image in mIF expressing 8 markers. In higher magnification is possible to observe the co expression of CK+Ki67+, CK PDL1, CD3+Foxp3+ and CD3+CD8+
Abstract 945 Table 1 Results: cell phenotypes in percentage in the six cases analyzed

\begin{tabular}{|c|c|c|c|c|c|c|}
\hline & EST01 & EST02 & ESTO3 & ESTO4 & EST05 & EST06 \\
\hline Total $\mathrm{CK}+(\mathrm{n} / \mathrm{mm} 2)$ & 82.06 & 1.64 & 5.73 & 85.18 & 69.93 & 91.43 \\
\hline $\mathrm{CK}+\mathrm{PD}-\mathrm{L} 1+(\mathrm{n} / \mathrm{mm} 2)$ & 0.18 & 45.22 & 7.57 & 0.11 & 0.29 & 0.03 \\
\hline $\mathrm{CK}+\mathrm{K} 167+(\mathrm{n} / \mathrm{mm} 2)$ & 16.64 & 4.23 & 3.57 & 14.01 & 11.49 & 4.69 \\
\hline Total CD3+ $(\mathrm{n} / \mathrm{mm} 2)$ & 0.71 & 43.63 & 28.39 & 0.74 & 0.43 & 0.36 \\
\hline CD3+CD8+ (n/mm2) & 10.24 & 6.84 & 8.27 & 14.02 & 32.63 & 24.14 \\
\hline CD3+PD-1+ $(\mathrm{n} / \mathrm{mm} 2)$ & 0.49 & 1.23 & 1.42 & 3.74 & 1.05 & 0.69 \\
\hline CD3+PD-11+ (n/mm2) & 0.00 & 0.01 & 0.00 & 0.00 & 0.00 & 0.00 \\
\hline CD3+K167+ (n/mm2) & 3.90 & 0.87 & 0.11 & 3.74 & 9.47 & 7.59 \\
\hline $\mathrm{CD}+\mathrm{CD} 8+\mathrm{K} 167+(\mathrm{n} / \mathrm{mm} 2)$ & 0.00 & 0.06 & 0.00 & 0.00 & 7.37 & 3.45 \\
\hline CD3+CD8+PD- $1+(\mathrm{n} / \mathrm{mm} 2)$ & 0.00 & 0.00 & 0.05 & 1.87 & 0.00 & 0.00 \\
\hline CD3+FOXP3+CD8- $(\mathrm{n} / \mathrm{mm} 2)$ & 42.44 & 2.09 & 4.86 & 11.68 & 11.58 & 5.52 \\
\hline Total CD68+ $(\mathrm{n} / \mathrm{mm} 2)$ & 15.15 & 7.23 & 1.00 & 9.00 & 14.28 & 2.48 \\
\hline CD68+PD-L1+ (n/mm2) & 0.00 & 0.00 & 0.00 & 0.04 & 0.00 & 00.00 \\
\hline Total Cells $(\mathrm{n} / \mathrm{mm} 2)$ & 4526.05 & 6888.64 & 12681.85 & 5370.87 & 4750.26 & 6370.19 \\
\hline Area of analysis $(\mathrm{n} / \mathrm{mm} 2)$ & 6.36 & 6.50 & 6.40 & 5.39 & 4.67 & 6.39 \\
\hline
\end{tabular}

Abstract 945 Table 2 Clinical data of the six patients. L: left . R: right, BR : Breast cáncer, CRC: Colorrectal cáncer, NE: No evaluable IDC : Invasive ductal carcinoma, CT: chemotherapy and BT : biotherapy

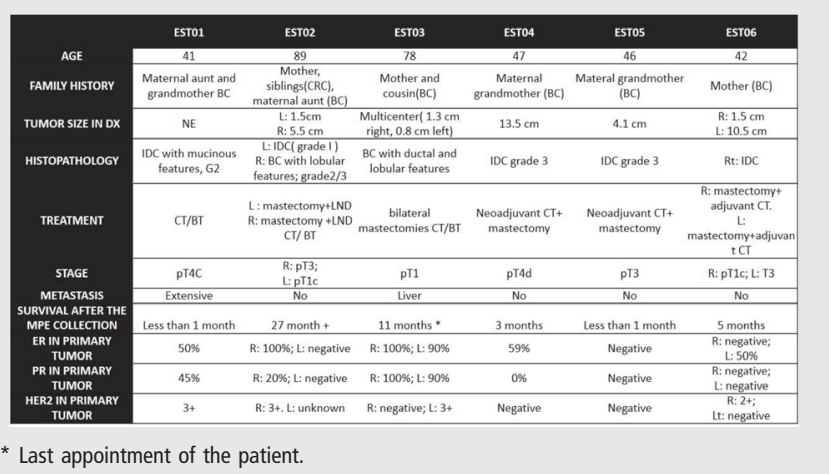

Methods Five microns thickness paraffin cell pellet blocks from six cases randomly selected of breast carcinoma MPE were stained using a quantitative multiplex immunofluorescence $(\mathrm{mIF})$ panel containing 8 markers against pancytokeratin (CK), PD-L1, PD-1, CD3, CD8, Foxp3, CD68, Ki67, and DAPI (figure 1). Representative regions of interest were scanned using a multispectral scanner (Vectra Polaris) in high magnification $(20 \mathrm{x})$ to capture different cell populations. Markers co-expression were processed and analyzed using a quantitative image analysis software (InForm). The final results were obtained as absolute number of cells from each phenotype and were characterized with clinicopathologic features.

Results We analyzed and stained six breast cancer MPE cases with previously optimized and validated mIF panel for formalin fixed and paraffin embedded (FFPE) tumor tissues against CK, CD3, CD68, CD8, Foxp3, Ki67, PD1 and PD-L1 (figure 2). The median cellular density was 5870.53 cells. Median for each marker: CK+ was presented in $75.9 \%$ (between malignant cells and reactive mesothelial cells) in these cells the expression of Ki67 was $8 \%$ and PD-L1+ was present in $0.2 \% . \mathrm{CD} 3+$ was $0.72 \%$ and being the cytotoxic $\mathrm{T}$ cells CD $3+\mathrm{CD} 8+$ was $12.13 \%$ of these cells and it expression for CD3+PD1+ was in $1.14 \%$ without concomitant expression for PD-L1. The median of the macrophages CD68+ was $8.1 \%$ of the total cells (table 2). 


\section{Abstracts}

Conclusions mIF is a promising tool to study diverse corporal effusion from different origin. Although more studies are needed, this new perspective can help us to resolve some clues and possible prognosis in advanced stages of BC.

\section{REFERENCE}

1. Nicholas D T, Matthew A. S. Diagnosis and Management of Pleural Metastases and Malignant Effusion in Breast Cancer.En: Kirby I B, Edward M C, V. Suzanne K, William J. G. The Breast (Fifth Edition): Elsevier; 2018. P 934.

http://dx.doi.org/10.1136/jitc-2021-SITC2021.945 